\title{
Specialization of Mathematic Teachers and Professional Development
}

\author{
Zhaohai WANG \\ Department of mathematics and statistics, Ankang University, Ankang, Shanxi 725000, China \\ akwzh@163.com
}

\begin{abstract}
The professional knowledge and skills which the professional teachers of mathematics needed are analyzed, as concludes fundamental methods to develop professionally for professional teachers of mathematics. To realize the specialization of a mathematics teacher and to enhance the professional development, one must do following actions, doing research actively, rethinking frequently, willing to communicate and good at learning. Therefore, our mathematics teacher would change from just a teacher into a real profession teacher. Our curriculum revolution in present situation would not become a mere formality. Moreover, our national mathematics education would have a real qualitative leap.
\end{abstract}

Index Terms - mathematics, professors, processionals, development

\section{Introduction}

Mathematics is the foundation of science and technology. And also it has made great contributions to business, government finance, citizen health and national security, opening the gate of universitystudents' careers while helping people to make decisions according to sufficient evidence. The world needs mathematical thinking more than ever. The development of mathematical ability largely depends on the education of mathematics. From new mathematics movement to problem solving, researchers have always been trying to find a better way to develop the mathematical ability of young generations since the reform of mathematics curriculum started all over the globe. However, existing reform movement in school neglected one thing obviously, which is that teachers do not know what they know, what they can do for the student, and what important role they are playing in developing the ability of students' mathematical abilities. In addition to advanced concept as guidance, teachers are the key to mathematics curriculum reform. Teachers are the executors, which mean that education reform would only be a beautiful halo if teachers do not participate in the revolution positively or they just admire the new ideas without any actual actions. Thus, building a group of highly qualified mathematics teachers is the key to mathematics education reform and the key to develop mathematical talents. What' more, specialization in mathematics profession is a common trend in the globe. [1]The Yearbook of World Education in the theme of Teacher Professional Development in 1980pointed out that there are two goals in teacher specialization. The first one is to take teacher as one class in our social stratification, and the goal would be trying to get the professional status and rights for themselves. The second one is that the teachers improve their teaching skills and enrich personal knowledge and skills.
However, there are large amount of research articles about the second goal, which focuses on the reforms of higher education. Generally speaking, most mathematics teachers (no matter young or old) think that pre-career training is about teaching skills not mathematical knowledge. And their teaching knowledge mainly comes from their own working experiences and rethinking, and communication with working partners. It gives evidence for higher education reform to pay attention to teachers' professional development. In other words, career specialization is not only one new understanding of the job itself but also the process of fighting. Standing at this point, we really should attach importance to the professional development of mathematics teachers.[2]

\section{Professional Knowledge and Skills of Mathematics Teacher}

One thing for sure as a professional mathematics teacher is that he must understand what professional knowledge he needs and what professional ability he has. In the 1992's International Conference of Mathematics Education, Rappan and Sealer Lu Binns emphasized that a mathematics teacher must acquire at least three types of knowledge which are mathematics, mathematical education and student to perform teaching activities effectively, and pointed out that mathematical teachers are teaching knowledge by standing at the special intersection of the different knowledge by thinking variously affected from different dimensions. As for today, mathematical education has become one relative independent discipline to some extent, and there are lots of people doing mathematical education research. We think that it is necessary to discuss the intersection of the different knowledge mentioned above more clearly. Specifically speaking, we conclude that a professional mathematics teacher must own the following knowledge at least.

\subsection{Philosophy of Mathematics Education}

The importance of mathematical philosophy to mathematics teaching is the same as the one of life philosophy and values to a person, which includes three questions. The first one is that what mathematics is. The second one is that why we teach mathematics. The third one is that how we teach mathematics. Comparing with the specific knowledge, the philosophy of mathematics emphasize that it is one part of meta-cognition which permeates epistemology and ontology.

\subsection{Disciplines of Mathematics Knowledge}

It is very hard to answer one question that how much 
mathematical knowledge a professional mathematics teacher really needs. But a well-organized warehouse of mathematical knowledge with sufficient supply is exactly what a professional mathematics teacher really needs, and its wellorganized construction is much more important than the knowledge itself. Standing at the top of the view, he can review the whole knowledge he taught, he can understand the connections inside the knowledge, and he must acquire the ability of changing mathematical knowledge into understandable knowledge. [3]Jingzhong Zhang, as a Chinese academician, to make mathematical knowledge become educational and understandable is not only the question of education but also the question of mathematics.

\subsection{Mathematics Pedagogy and Educational Psychology of Mathematics}

The knowledge that a mathematics teacher maintained is not only about pedagogy and psychology but also the combination of those two. From the mathematics teaching methods in the beginning to mathematics education research in present day, mathematics pedagogy has become a relative mature subject. We only paid attention to teaching methods and neglected the psychology of the students when they were learning mathematics. Although some teaching experiences had been concluded, it lacks of research on the psychology from the students during the learning process. Thus, it cannot be summarized in a theoretical level as development and application. Based on more and more empirical study, teachers can help learners acquire mathematical knowledge and develop the mathematics abilities more effectively and more efficiently only by understanding the psychology of students more clearly. [4]

\subsection{Educating Technology of Mathematics}

Even though educating technology of mathematics is listed as one independent item, some previous researchers merely discussed about the technical knowledge of teachers. More importantly, modern information technology has already touched the problems of what to teach and how to teach. However, there are only $27.2 \%$ of our teachers often use computers as assistant teaching method, according to the researches of the mathematics teachers in China. A professional mathematics teacher would use information techniques to teach students, combining information technology with mathematics into one, and he could teach students using information techniques to discover mathematics and to create them.

\subsection{Common Knowledge}

As for the teacher's ability, common knowledge is also playing an important role, because teachers are always facing living persons when they are teaching. Education performance and education situation are happened randomly and differently, so there are no fixed patterns and techniques for teachers to follow. He must use his own academic background and teaching experience to make decisions and judgments creatively according to flexible education situations, which needs one's comprehensive ability.

\section{Professional Development of Mathematics Teacher}

Researchers are always trying to discover certain patterns of teacher's professional development since from a long time. And different professional patterns represent different developmental directions and goals. Specifically speaking, there three patterns to for teachers to learn and to follow, such as the pattern of the skilled, the pattern of research practitioner, and the pattern of reflective practitioner. [5]People from the first pattern think that teaching process is like medication and engineering, whose characteristics lies in the practice of scientific knowledge, maturity of technology and the empirical results. Also it is proved that the property of a professional teacher could be passed onto certain normal teachers, which would give help to develop professionally and become talented. People from the pattern of the skilled proposed that there must be united teaching standards for teachers to follow and they have no rights and permissions to create new things by themselves, which maintain a dominant position. However, the most important sources for teacher's professional development come from teacher's own experience and rethinking process according researches in China and foreign countries, not so-called special training from the professionals and experts. Knowledge of professional teachers is mostly personalized and reticent, as cannot be passed onto others formally and comprehensively. They are only formed by the subject in the process of dealing with complex and uncertain education situations. In other words, teachers are often in the situation of random and temperate, which means that education situation is complicated and full of uncertainty and chaos. No doubt that there are some necessary skills a teacher must have, the education ability seems to be more important as for a teacher. Therefore, the professional development of mathematics teachers must transform its pattern.

\subsection{Mathematics Teacher as Researcher}

Due to the uncertainty of education situations, mathematics teacher shall not only be a practitioner but also a researcher. One must think twice before $h^{\wedge} \%$ thought that teacher is the head of the classroom. From the point of view of Aristotelean, classroom seems to be an ideal laboratory to exam teaching theory. And one has to admit that teachers have large amount of opportunities to do teaching research. A professional mathematics teacher should not consider the classroom as a low class drill, but he will make his own classroom a comprehensive explore. And one must perform revolutionary experiments of mathematical education independently, which contains new, efficient and low consumption methods of mathematics teaching with the purposes of quality education. Teaching methods of Qingfu and MM are all good, which are concluded from the front line teachers. Besides, mathematical researches must be done continuously. All best teachers had done some research work in the past careers. During the process of doing research work, the teachers will deepen their thoughts about mathematics thinking method and complete mathematics knowledge 
system. Then they also might find certain common connections behind knowledge, and give out new solutions about some famous mathematical problems. Elementary mathematics should be a good research direction for middle school mathematics teachers. Jingzhong Zhang, as Chinese academician, had concluded new solutions of area methods to geometrical problems when he was teaching in a middle school through the research of geometry, and its application in machines proved to be a great success.

\subsection{Mathematics Teacher as Reflective Practitioner}

Mathematics teacher must be a researchers and a reflective practitioner. John Dewey thought that teacher should have proper doubt about teaching itself without any arguments and just change one teaching method into another one. And they must have reflective action for teaching. We conclude that one, as a professional mathematics teacher, not only maintain classroom teaching methods, techniques, and skills, but also maintain rethinking about belief system, teaching method, teaching contents, mathematics knowledge system, background factors. Thus, those activities will make teachers under rational control and maintain a status of dynamic, open and continuing development. The role of a reflective mathematics teacher is very important in today's new discipline reform. We think that the new discipline reform is not just movement of the experts, but it is a movement about combination of theory and practice and combination of experts and teachers. The new curriculum standards proposed many new concepts about shortcomings during the mathematics teaching, such as, real, interesting, and challenging mathematics learning content, making students to explore by themselves and so on. Although the new concepts as good medicine to cure traditional teaching. However, every teacher should know how to balance during the specific teaching process. If real situation is introduced into the classroom and submerge the mathematical knowledge in a large number of examples from real life or only pay attention to cultivating students' ability of supposition, neglecting the complicated evidence, our mathematics lesson will lose its meaning. Students will learn nothing about mathematics. Only through reflective practice, the mathematics teacher will find the balance to develop students' mathematical ability comprehensively. Also people should rethink about the new teaching materials. Teachers must participate into the education reform, giving objective comments about new curriculum reform through reflective practice. Our reform will be successful; our mathematics education will face vigorous development.

\subsection{Building Mathematics Teacher Community}

Except for teacher's own experience and reflective thinking, the communication with colleges is also an important source of teacher's professional knowledge. Thus, to found mathematics teacher community is very necessary. The foundation of Teacher Community could make up shortcomings of the individuals, helping critical reflection consciousness to spread. Mathematics teachers of one Grade, one school, and one area should form organization as a community, which helps to perform better communication and cooperation. Teachers could have more and more research and discussion about professional practice. We should create the community conditions, such as to enhance the plan of master and apprentice, to work together in one area, and to set up regular mathematics seminar and so on. Teacher may jump out his own narrow space and realize better professional development.

\subsection{Continuing Training of Mathematics Teacher}

Although professional knowledge mainly comes from teacher's experience and rethinking, the continuing training for mathematics teacher cannot be neglected. Even if there is a whole set of training program for teachers in China, the requirements cannot meet modern needs. And there are several phenomena to represent. Career training put too much weight on certification than ability. Most of the teachers think that this kind of education is just for certification without any meaningful purposes. Curriculums and teaching methods of the continuing training are behind, which are still using old fashioned methods and simple. What's more, teachers who went through independent learning and cooperative learning could use them more effectively in the classroom. However, training duration is short, as is always occupying the holiday time of teachers. We think that teachers could do a few years of teaching practice and then do full-time study for half of a year, which would help them doing learning process systemically. As for the training program of mathematics teachers, we suggest that there are some points that can be noticed.

(1) Change certification education into the one of knowledge ability.

(2) Training of mathematics knowledge is not the repeat of university knowledge. It is closely related middle school knowledge, originates from the middle school knowledge and higher than the middle school mathematics knowledge.

(3) Training must be based on personal experience, which causes teacher's resonance. And the theoretical knowledge will be changed into practice.

(4) Strengthen the modernization of technical training.

Generally speaking, continuing training is the duty of mathematics teacher and also the right of them. Only a well trained professional mathematics teacher could realize professional development better.

\section{References}

[1] Teaching Department of Education Ministry. Theory and Practice of Teacher Specialization. Beijing: People's Education Press, 2003.

[2] Stephen D. Brookfield. Becoming a Critically Reflective Teacher. Beijing: China Light Industry Press, 2002.

[3] Lianghuo Fan. Study on the Development of Teaching Knowledge of Teachers. Shanghai: East China Normal University Press, 2003.

[4] Wenxuan Shen. Research on Professional Specialization of Mathematics Teachers and Mathematics Education. Middle School Mathematics,2004: (2)1

[5] Zixing Wang. Research on Connotation of Mathematics Teachers' Specialization. Journal of Mathematics Education, 2002(11). 